\title{
Slip-Sliding the Frame: Programmed -1 Frameshifting on Eukaryotic Transcripts
}

\author{
Gerald M. Wilson and Gary Brewer ${ }^{1}$ \\ Department of Microbiology and Immunology, Wake Forest University School of Medicine, Winston-Salem, North Carolina 27157-1064 USA
}

$\mathbf{T}_{\mathrm{r}}$ he basic mechanisms of mRNA translation are ubiquitous among all organisms, in that the accurate decoding of triplet codon sequences programs serial amide linkages of amino acid residues by ribosomal complexes. In general, the fidelity of this process is dependent on both accurate recognition of mRNA codons by aminoacyl tRNAs and maintenance of the corresponding open reading frame. However, in a growing number of cases, deviations from this triplet codon rule are observed, indicating that the information content of an mRNA to encode protein may extend beyond its primary structure. These cases, collectively referred to as translational recoding (for review, see Gesteland and Atkins 1996), present exceptions to the venerable genetic code and are typically subdivided among three primary mechanisms: (1) frameshifting, in which translating ribosomes are induced to slide one nucleotide forward or backward at a distinct point in the transcript, with protein synthesis then continuing in the +1 or -1 reading frame, respectively; (2) alternative codon usage, where stop codons are not interpreted as sites of translational termination but, rather, encode an amino acid residue; and (3) translational bypassing, where the translational machinery traverses a gap in the mRNA coding sequence yet yields a single polypeptide chain.

Programmed -1 ribosomal frameshift signals are among the most extensively characterized of these translational recoding phenomena (for review, see Brierly 1995; Dinman 1995; Farabaugh 1996). Although current examples are largely limited to viral sys-

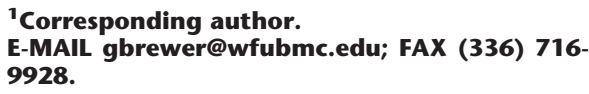

tems, some bacterial - 1 frameshifting events have also been documented (Blinkowa and Walker 1990; Tsuchihashi and Brown 1992; Chandler and Fayet 1993; Engelberg-Kulka and Schoulaker-Schwarz 1994). At present, no examples of eukaryotic mRNAs exhibiting -1 frameshift activity have been reported. However, a number of viruses infecting eukaryotic cells utilize programmed -1 ribosomal frameshifts, demonstrating that the cis elements involved in the frameshifting process are operational in eukaryotes. In viral systems, the efficiency of frameshifting is an essential determinant of the stoichiometry of synthesized viral protein products, which must be rigidly maintained for efficient propagation of the virus (Brierly 1995 and references therein; Dinman and Wickner 1995).

In work presented in this issue, (Hammell et al. 1999), a bioinformatic approach was used to screen prokaryotic and eukaryotic DNA sequence databases for potential -1 frameshift signals. Because of the complexity of -1 frameshift sites and the sequence variability observed among these elements in nature, a multicomponent search algorithm was required to identify candidate sites from bulk database entries. This was made possible in part by the plethora of information available describing structural features of frameshift signals, much of which is described in Hammell et al. (1999) and elsewhere (Brierly 1995; Chen et al. 1996; Marczinke et al. 1998). This strategy represents a marked contrast to many examples of database searching, which typically involve a single motif or are limited to primary structure parameters (Fickett 1996; Altschul et al. 1997; Aravind and Landsman 1998; O’Neill 1998).
Database searches using this compound algorithm for -1 frameshift sites yielded a host of potential signals in all databases tested, including eukaryotic sequences, with frequencies significantly higher than found in random sequence populations. In a number of cases, frameshift signals were conserved in homologous mRNAs from different species. A convincing argument for the validity of these searches was provided by the functional demonstration of -1 frameshifting activity for two selected signals (from Saccharomyces cerevisiae RAS1 and human CCR5 mRNAs) in a recombinant assay system. Furthermore, in four cases, potential -1 frameshift signals colocalized to sites of mutation linked to heritable diseases in humans, raising the possibility that -1 frameshift activity may be a physiologically relevant component of regulated gene expression in humans. Modifications of the parameters employed in this search algorithm may yet reveal additional candidate frameshift signals, as the potential for 3'-RNA pseudoknot formation was a constraint placed upon their selection in this study. An RNA pseudoknot is not requisite for -1 frameshifting at the gag-pol overlap of HIV-1 (Jacks et al. 1988), for example, which only contains a weak 3'-stem-loop structure in vivo (Parkin et al. 1992).

The identification of functional -1 frameshift signals in chromosomally encoded eukaryotic mRNAs raises several interesting questions for further investigation. First, it will be important to determine if ribosomal frameshifting occurs in vivo in the context of these transcripts. If so, what is the function of the frameshift event? A ribosomal frameshift may serve to generate alternate protein isoforms, with common amino- 
terminal sequences but distinct carboxyterminal regions. Protein products containing alternatively framed moieties may present unique functional features or may be subject to different modes of regulatory control. In other cases, frameshifting events may have more direct regulatory roles. For example, frameshifts could result in premature termination of protein synthesis if the frameshift generates a stop codon in the -1 open reading frame. In this case, the mRNA may be subject to accelerated turnover by the nonsense-mediated mRNA decay pathway (for review, see Maquat 1995; Jacobson and Peltz 1996; Ruiz-Echevarria et al. 1996). Another question regarding eukaryotic frameshifting events is whether their efficiency may be regulated in response to signaling pathways or other stimuli. This is particularly applicable in the context of multicellular organisms, whose control of gene expression is often subject to a host of endocrine and developmental effects.

If programmed -1 ribosomal frameshifting does not occur with eukaryotic mRNAs, it is possible that flanking sequences may have evolved to repress this activity. Alternatively, specific trans-acting factors may participate in the repression of frameshifting events on eukaryotic transcripts. For example, the MOF2/SUI1 gene product of $S$. cerevisiae functions as an inhibitor of viral RNA frameshifting in infected yeast cells (Cui et al. 1998). This function is well conserved, as a yeast mof2 mutant can be rescued by the human homolog of SUI1. Maintenance of the translational reading frame in yeast can also be influenced by 5S rRNA (Dinman and Wickner 1995), Upf1p (Cui et al. 1996), and Upf3p (Ruiz-Echevarria et al. 1998). It is possible that a subset of such factors may function to promote general translational fidelity but are compromised during viral infection or some regulatory event.
Despite the identification of programmed -1 ribosomal frameshifting activity associated with human mRNA sequences, the possibility of developing antiviral therapeutic strategies targeting this mechanism remains an intriguing possibility (Dinman et al. 1997, 1998; Hung et al. 1998). For example, compounds that modulate the stability of either the downstream RNA structural motif or codon/anticodon interactions may alter the efficiency of frameshifting events, leading to a change in the ratio of frameshifted/nonshifted viral proteins. Because the function of the RNA pseudoknot structure may involve retarding translating ribosomes at the frameshift site (for review, see Brierly 1995; Farabaugh 1996), compounds modulating the kinetics of translational elongation may similarly influence frameshit efficiency. Obviously, the implications for modulation of host gene expression must also be considered in the development of such therapies, but even modest changes in viral frameshifting efficiency may be sufficient to confer significant host benefit. This was demonstrated using LA virus infection of yeast, where up- or down-regulation of frameshifting efficiency by more than twofold prevented viral propagation (Dinman and Wickner 1995). Extrapolating to the possibility that alterations in programmed -1 frameshifting may also contribute to human genetic disorders, similar strategies aimed at modulating the frameshift efficiencies of endogenous mRNAs may offer some therapeutic utility.

\section{REFERENCES}

Altschul, S.F., T.L. Madden, A.A. Schäffer, J. Zhang, Z. Zhang, W. Miller, and D.J. Lipman. 1997. Nucleic Acids Res. 25: 3389-3402.

Aravind, L. and D. Landsman. 1998. Nucleic Acids Res. 26: 4413-4421.

Blinkowa, A.L. and J.R. Walker. 1990. Nucleic Acids Res. 18: 1725-1729.
Brierly, I. 1995. J. Gen. Virol. 76: $1885-$ 1892.

Chandler, M. and O. Fayet. 1993. Mol. Microbiol. 7: 497-503.

Chen, X., H. Kang, L.X. Shen, M. Chamorro, H.E. Varmus, and I. Tinoco, Jr. 1996. J. Mol. Biol. 260: 479-483.

Cui, Y., J.D. Dinman, and S.W. Peltz. 1996. ЕМВO J. 15: 5726-5736.

Cui, Y., J.D. Dinman, T.G. Kinzy, and S.W. Peltz. 1998. Mol. Cell. Biol.

18: 1506-1516.

Dinman, J.D. 1995. Yeast 11: 1115-1127.

Dinman, J.D. and R.B. Wickner. 1995. Genetics 141: 95-105.

Dinman, J.D., M.J. Ruiz-Echevarria, K. Czaplinski, and S.W. Peltz. 1997. Proc. Natl. Acad. Sci. 94: 6606-6611.

Dinman, J.D., M.J. Ruiz-Echevarria, and S.W. Peltz. 1998. Trends Biotechnol. 16: 190-196.

Engelberg-Kulka, H. and R. Schoulaker-Schwarz. 1994. Mol. Microbiol. 11: $3-8$.

Farabaugh, P.J. 1996. Annu. Rev. Genet. 30: 507-528.

Fickett, J.W. 1996. Trends Genet. 12: 316-320.

Gesteland, R.F. and J.F. Atkins. 1996. Annu. Rev. Biochem. 65: 741-768.

Hammell, A.B., R.C. Taylor, S.W. Peltz, and J.D. Dinman. 1999. Genome Res. (this issue).

Hung, M., P. Patel, S. Davis, and S.R. Green. 1998. J. Virol. 72: 4819-4824.

Jacks, T., M.D. Power, F.R. Masiarz, P.A. Luciw, P.J. Barr, and H.E. Varmus. 1988. Nature 331: 280-283.

Jacobson, A. and S.W. Peltz. 1996. Annu. Rev. Biochem. 65: 693-739.

Maquat, L.E. 1995. RNA 1: 453-465.

Marczinke, B., R. Fisher, M. Vidakovic, A.J. Bloys, and I. Brierly. 1998. J. Mol. Biol. 284: 205-225.

O'Neill, M.C. 1998. Proc. Natl. Acad. Sci. 95: 10710-10715.

Parkin, N.T., M. Chamorro, and H.E. Varmus. 1992. J. Virol. 66: 5147-5151.

Ruiz-Echevarria, M.J., K. Czaplinski, and S.W. Peltz. 1996. Trends Biochem. Sci. 21: 433-438.

Ruiz-Echevarria, M.J., J.M. Yasenchak, X. Han, J.D. Dinman, and S.W. Peltz. 1998. Proc. Natl. Acad. Sci. 95: $8721-8726$.

Tsuchihashi, Z. and P.O. Brown. 1992. Genes \& Dev. 6: 511-519. 


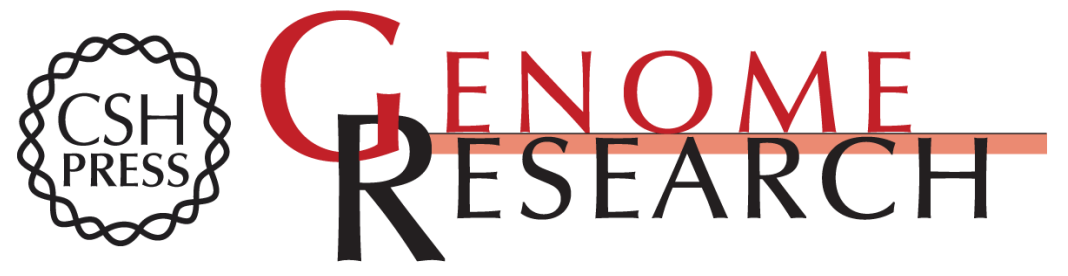

\section{Slip-Sliding the Frame: Programmed -1 Frameshifting on Eukaryotic Transcripts}

Gerald M. Wilson and Gary Brewer

Genome Res. 1999 9: 393-394

Access the most recent version at doi:10.1101/gr.9.5.393

References This article cites 26 articles, 9 of which can be accessed free at:

http://genome.cshlp.org/content/9/5/393.full.html\#ref-list-1

\section{License}

Email Alerting Receive free email alerts when new articles cite this article - sign up in the box at the Service top right corner of the article or click here.

\section{Affordable, Accurate Sequencing.}

To subscribe to Genome Research go to: https://genome.cshlp.org/subscriptions 